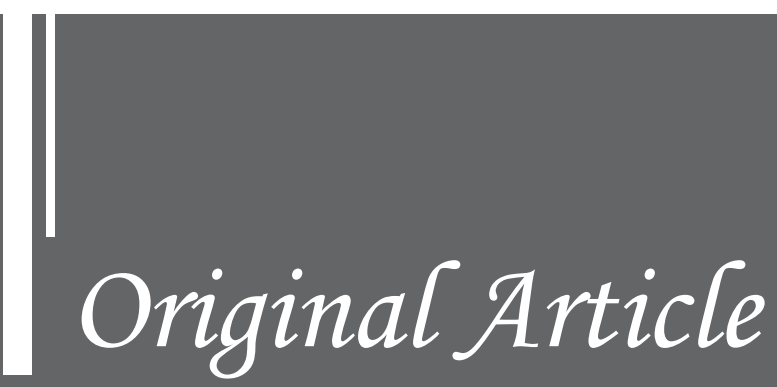

\title{
IMPROVING FOOD AND NUTRITION SECURITY OF VULNERAB LE COMMUNITIES - AN INTEGRATED NUTRITION SENSITIVE APPROACH
}

\author{
Aaliya Habib ${ }^{1}$, Muhammad Aslam Bajwa², Naureen Omer ${ }^{2}$, Omer \\ Ahmed Bangash ${ }^{3}$, Zulfiqar Ahmed ${ }^{3}$
}

${ }^{1}$ Nutrition International

${ }^{2} \mathrm{FMH}$ College of Medicine and Dentistry

${ }^{3}$ Welthungerhilfe (WHH)

Correspondence: Aaliya Habib .Email: habibaaliyah@gmail.com

\begin{abstract}
Background: Food and Nutrition Security is a multilevel and complex construct, needing a holistic developmental approach, including multiple stakeholders. These projects were implemented by local partners, Lasoona and Doaba Foundation addressing food availability, access, use, utilization, and sustainability through a multi-sectoral approach. The aim of the evaluation was to provide a comprehensive assessment of Food and Nutrition Security projects (1086 and 1087) based on OECD DAC evaluation criteria.

Methods: Mixed method approach, quasi-experimental design was used, including desk review, key informant interviews, focus group discussions with target communities, structured interviews of beneficiaries using Household Food Insecurity Assessment Scale (HIFAS) and Months of Adequate Household Food Provisioning (MAHFP) scale.

Results: According to the HIFAS results, Districts of Khyber Pakhtunkhwa (KP) including Kohistan \& Sawat were vulnerable with $34 \%$ and $15.78 \%$ households facing food insecurity respectively. While in Muzaffargarh, a district of Punjab, 47\% households were facing food insecurity. HDDS and IDDS improved considerably in all districts of KP and Punjab.

Conclusion: The evaluated projects were social change projects sowing the seeds of a major social paradigm shift - changing the status of women at household and community level. Awareness of malnutrition and balanced diet through community volunteers, peer educators, social mobilizers and outreach workers played a pivotal role. Access and availability of diversified and nutritious food via kitchen gardens and plantation of trees with the use of organic fertilizers was encouraged.

Keywords: Food and nutrition security, community empowerment, integrated multisectoral approach to malnutrition
\end{abstract}




\section{Introduction}

Deutsche Welthungerhilfe (DWHH) is a German based, non-profit making, non-aligned, international Non-Government Organization (NGO) that aspires to see a world without hunger and poverty. In Pakistan, DWHH is implementing the Multi-Annua (1) Country Programme 2016 - 2018, in three main sectors: 1) Humanitarian Aid, 2) Food and Nutrition Security and 3) Capacity Development(2), Empowerment and Support in provinces of Khyber Pakhtunkhwa (KP), Punjab and Sindh in Pakistan.

In $2013 \mathrm{WHH}$, in collaboration with a long-term local partner in Khyber Pakhtunkhwa (KP) - Lasoona- began a three-year Food Nutrition Security project in 21 villages of Swat, Shangla and Kohistan, districts of Khyber Pakhtunkhwa (KP)(3). The project, PAK 1064, addressed food availability, access, use and utilization, and sustainability through a multi-sectoral approach. The project piloted different approaches for improving food and nutrition security status of the target communities, measured through proxy indicators of Household Dietary Diversity Score (HDDS)(4)and Individual Dietary Diversity Score (IDDS)(5) at baseline and end line. A similar Food and Nutrition Security (FNS) project, PAK 1065, was implemented in four Union Councils of Muzaffargarh district, Punjab; in partnership with Doaba Foundation, an NGO working in riverine area of Muzaffargarh (6).

Both the projects used community embedded, integrated developmental approaches for implementing food and nutrition security interventions ranging from food diversification gardens, school /children clubs, infrastructure support, enterprise development trainings, trainings for reducing post-harvest losses, improving crops' yield and management, behavior change communication for changing dietary habits and most importantly community empowerment through the formation of Community Based Organizations.

The projects successfully improved the nutrition and food security situation in the target areas, measured through end line surveys. The external evaluation of the projects in September 2016, was extremely positive about the relevance, effectiveness, efficiency, and sustainability of the project. It recommended the continuation of FNS work to increase the impact and sustainability. The projects (1086 in Khyber Pakhtunkhwa and 1087 in Punjab) which are the subject of this evaluation, were the Phase 2 of these projects.

Project 1086 was implemented in 7 Union Councils of Swat, Shangla and Kohistan districts in KP from December 2016 to November 2018 Project 1087 was implemented in ten new villages of Muzaffargarh district from December 2016 to January 2019 in Southern Punjab. Phase 2 projects, while continuing the successful interventions of Phase 1, were geared more towards ensuring sustainability by enhancing community ownership and connecting with existing government infrastructure of relevant departments at district and union council levels.

National Nutrition Survey 2011 ( the frame of reference for the projects) revealed that almost $58 \%$ households were food insecure. Half of adult women had anaemia and calcium deficiency and nearly two-thirds were deficient in vitamin D. $44 \%$ of children under the age of 5 years were stunted, about $15 \%$ of children under five years had severe and moderate acute malnutrition requiring urgent clinical care and one third (1/3) of children were underweight. Phase 2 was more about the institutionalization of Food and Nutrition Security efforts undertaken by WHH and its partners in two very different geographical areas of Pakistan and to demonstrate to the government effectiveness of FNS interventions for addressing malnutrition crisis facing the country. The objective of the evaluation was to provide a comprehensive assessment of the Food Nutrition Security projects based on OECD DAC (Organization For Economic Co-Operation And Development Development Assistance Committee) 7criteria.

Methodology

The evaluation had mixed methods, quasi-experimental design. The target group of Project 1086 in KP belonged to lower income and poor communities of Swat, Shangla and Kohistan districts while the target group of Project 1087 was the poor riverine population of Muzaffargarh district. The pregnant and lactating women and children under 2 years were the "impact population" of both projects.

Sampling was done in two phases. For quantitative sampling Lot Quality Assurance (LQAS) (8) method was adopted. As a sample of 19 is an acceptable level for making management decisions, at least $92 \%$ of the time. Two intervention Union Councils from each target district were selected and called a 'supervision area' and district was the 'supervision unit'. Using the household database provided by DWHH, the consultant randomly selected 38 interviews from each project district in KP and Punjab, while selecting 19 households from all villages by using simple random sampling from each selected Union Council. A total of 152 household survey were conducted, 114 from KP target districts and 38 from Punjab target district.

For qualitative sampling focus group discussions (FGD) and key informant interviews (KII) were used to provide an in-depth, contextualized understanding of the dynamics of change from the perspectives of projects' stakeholders. A total of 22 FGDs and 19 KIIs were conducted with the implementers, beneficiaries and key stakeholders. The FGDs were conducted with the groups of men and women from the target communities, whereas the KIIs were conducted with key stakeholders of the projects - Government representatives, Community Influential, Civil Society Organizations - and managements of Lasoona, Doaba and WHH.

Internationally validated qualitative tool Household Food Insecurity Assessment Scale (HIFAS) (9) was used to collect information about the impact of projects' interventions on reducing food insecurity in the target communities. The questionnaire consists of nine occurrence questions that represents a generally increasing level of severity of food insecurity (access), and nine "frequency-of-occurrence" questions that are asked as a follow-up to each occurrence question to determine how often the condition occurred. Two items of "Months of Adequate Household Food Provisioning (MAHFP)(10)" scale were included in the Household survey tool along with the demographic information. Evaluation was conducted using the OECD DAC Criteria evaluation tool based on five criteria's, relevance, effectiveness. efficiency, impact and sustainability. Tools after finalization was translated in Urdu, for easy understanding of the data collectors.

Quantitative data was analyzed on SPSS while for qualitative data analysis software QDA Miner Lite using thematic analysis was used. Data was fragmented through coding; abstract categories were constructed through these codes which explained the data and offered conceptual analysis of them. The data was categorized under subthemes which were clubbed under broader over-arching themes regarding different types, manifestations and dimensions of food and nutrition security as perceived and practiced by communities and stakeholders. The qualitative data- audio recordings of FGDs, IDIs and KIIs were transcribed verbatim and translated in English. Verbal consents were taken before data collection.

\section{Results}

The HIFAS Access related variable is a proxy for household poverty and measures food insecurity linked to poverty (lack of resources). Among Project 1086 target districts, Kohistan is the most vulnerable with $34 \%$ households facing food insecurity but only $5 \%$ of these have experienced it more than 10 times in last 4 weeks (often). In Muzaffargarh (Project 1087 target district) 47\% households feel food insecure but majority $42 \%$ have experienced it only once or twice in the last 4 weeks (rarely). This relates to the fact that people living in more vulnerable and disaster-prone areas have become psychologically tuned to worry and feel insecure. (Table 1)

The HIFAS domain related to food quality shows a pattern coinciding with the anxiety and uncertainty domain. This domain explores the perception of respondents related to food quality, including access to foods of one's choice and liking. Respondents from Kohistan and Muzaffargarh were not satisfied with the quality of food. Even the respondents from Shangla district, who haven't reported any anxiety about food insecurity also showed certain levels of dissatisfaction on the food quality domains. (Table 1)

The HFIAS score is a continuous measure of the degree of food insecurity (access) in the household in the past four weeks (30 days). The maximum score for a household is 27 (the household response to all nine frequency-of-occurrence questions was "often", coded with response code of 3 ); the minimum score is 0 (the household responded "no" to all occurrence questions). The higher the score, the more food insecurity (access) the household experienced. The lower the score, the less food insecurity (access) a household experienced. (Table 2)

The HIFAS score was 22 in Kohistan,(12) in Swat, 6 in Shangla and the maximum was 18 in Muzaffargarh. The HIFAS score for Swat and Shangla shows that household in both districts are mostly food secure. The average HIFAS score is also higher for Kohistan (6.3) and Muzaffargarh (5.7). Though the average scores of these districts are on 
the lower side but this indicates that concentrated efforts are needed for improving the food insecurity situation in these areas.

The food insecurity prevalence indicators reveal that majority of households in Swat and Shangla are food secure $61 \%$ and $63 \%$ respectively). But the situation of food insecurity appears to be quite serious in Kohistan, with $84 \%$ experiencing food insecurity, of which $42 \%$ were severely food insecure. Similarly, more than half $(66 \%)$ of the respondent households are food insecure in Muzaffargarh, of which majority $(47 \%)$ falls in severe category. (Table 2 )

The data shows that in the project's target districts in Khyber Pakhtunkhwa the food security has increased from ten months to eleven months during the project and has sustained at eleven months of food security by the time of evaluation. The situation issimilar in the project district of Punjab with food security sustaining at 10 months as compared to 8 months of adequate food provision at the baseline. (Figure 1)

A district wise analysis of KP project districts shows that Kohistan district has 10 months of adequate food provision, which is lowest among the three target districts, Shangla and Swat districts have year round food provision. Kohistan is the most difficult of the three- project district, culturally as well as geographically. (Table 3 )

Some key verbatims from FGDs and KIIs were as follows:

"Poverty and unemployment are two main issues /problems in our area, while Lasoona has created employment opportunities through different trainings and by building skills of the people." (Male FGD, Kohistan)

"Flood is the biggest problem of our area, road is unpaved, we don't have a middle school or hospital in our village. Doaba helped us in building raised platforms to have safety during floods. They provided us phone numbers of Head Trimou administration, so we can get early flood warning. They taught us to store fruit and vegetables for the lean days when people are out of work due to floods. Our women are self confident now and our decisions are given importance. Our daughter are going to school now. The thinking of our menfolk have changed." (Women FGD, Muzaffargarh)

We got the project for Shangla district which helped us to understand the food security intervention concept. Similarly in 2003, same interventions were implemented in Barani area of Kohistan, KP. These two projects transformed Lasoona's vision from environment and forestry to Food Security agriculture and poverty alleviation. In 2006, we developed our strategic plan; food security and sustainable livelihood were the main component of the strategy." (Lassona Management)

".....we learned about natural fertilizers from Lasoona........ Now we are following this method, our plants of one year look like as if they are 3,4 years old. Previously we were not aware of this sequence. Now we plant by following the taught method and used this fertilizer, it increases growth of plants. Lasoona) have taught us to use cartons. And also provided us cartons, so it became easier and sell our fruits at higher rates and get more profit." (Men FGD- Swat)

We came to know that if food and nutrition would be secure, only then community's resilience can increase When there is flood, it washes away all the assets and livelihood of the community but also causes acute malnutrition, which no body is watching out for. We learned that if resilience is to be build and the concept of "living with flood" is basically securing food and nutrition during floods" (Doaba Management)

Table 1: Household Food Insecurity Access- related Conditions and Access-related Domains

\begin{tabular}{|c|c|c|c|c|c|c|}
\hline \multirow[t]{2}{*}{ Sr.\# } & \multirow{2}{*}{\multicolumn{2}{|c|}{ Parameter }} & \multicolumn{4}{|c|}{ Districts } \\
\hline & & & Kohistan & Swat & Shangla & Muzaffargarh \\
\hline \multicolumn{7}{|c|}{ Household Food Insecurity Access-related Conditions } \\
\hline 1. & \multicolumn{2}{|c|}{$\begin{array}{l}\text { Household Food Insecurity Access- } \\
\text { related Conditions }\end{array}$} & $34.21 \%$ & $15.78 \%$ & $0 \%$ & $47.36 \%$ \\
\hline 2. & \multicolumn{2}{|c|}{$\begin{array}{l}\text { Households experiencing condition } \\
\text { Rarely }\end{array}$} & $26 \%$ & $5 \%$ & $0 \%$ & $42 \%$ \\
\hline 3. & \multicolumn{2}{|c|}{$\begin{array}{l}\text { Households experiencing condition } \\
\text { Sometimes }\end{array}$} & $3 \%$ & $11 \%$ & $0 \%$ & $5 \%$ \\
\hline 4. & \multicolumn{2}{|c|}{$\begin{array}{l}\text { Households experiencing condition } \\
\text { Often }\end{array}$} & $5 \%$ & $0 \%$ & $0 \%$ & $2 \%$ \\
\hline \multicolumn{7}{|c|}{ II. Household Food Insecurity Access-related Domains } \\
\hline 1. & \multirow{3}{*}{\begin{tabular}{|l|} 
Household Food \\
Insecurity \\
Access-related \\
Domains
\end{tabular}} & $\begin{array}{l}\text { Preferred Food } \\
\text { Choice }\end{array}$ & $81.57 \%$ & $31.57 \%$ & $34.21 \%$ & $55.26 \%$ \\
\hline 2. & & $\begin{array}{l}\text { Limited Food } \\
\text { Variety }\end{array}$ & $52.63 \%$ & $21.05 \%$ & $10.52 \%$ & $50 \%$ \\
\hline 3. & & $\begin{array}{l}\text { Eating disliked } \\
\text { food }\end{array}$ & $57.89 \%$ & $23.68 \%$ & $05.26 \%$ & $55 \%$ \\
\hline
\end{tabular}

Table 2: Household Food Insecurity Access Scale Score and Household Food Insecurity Access Prevalence

\begin{tabular}{|c|c|c|c|c|c|}
\hline & \multirow{2}{*}{ Parameter } & \multicolumn{4}{|c|}{ Districts } \\
\hline \# & & Kohistan & Swat & Shangla & Muzaffargarh \\
\hline \multicolumn{6}{|c|}{ Household Food Insecurity Access Scale Score } \\
\hline 1. & $\begin{array}{l}\text { HFIAS Score (0-27) } \\
\text { (Sum frequency-of- } \\
\text { occurrence question } \\
\text { response code) }\end{array}$ & 239 & 91 & 34 & 216 \\
\hline 2. & Average HFIAS Score & 6.3 & 2.4 & 0.89 & 5.7 \\
\hline \multicolumn{6}{|c|}{ II. Household Food Insecurity Access Prevalence } \\
\hline 1. & Food Secure & $16 \%$ & $61 \%$ & $63 \%$ & $34 \%$ \\
\hline 2. & Mild food insecurity & $29 \%$ & $3 \%$ & $24 \%$ & $11 \%$ \\
\hline 3. & Moderate food insecurity & $13 \%$ & $21 \%$ & $13 \%$ & $8 \%$ \\
\hline 4. & Severe food insecurity & $42 \%$ & $16 \%$ & $0 \%$ & $47 \%$ \\
\hline
\end{tabular}

MONTHS OF ADEQUATE HOUSEHOLD FOOD PROVISIONING (MAHFP)

$--1086--1087$

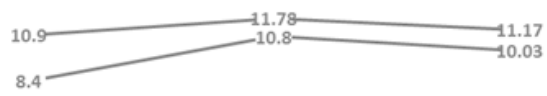

$\begin{array}{lll}\text { August - September } 2017 & \text { Apr-18 } & \text { Apr-19 }\end{array}$

Figure 1: Months of Adequate Household Food Provisioning (MAHFP)

Table 3: Months of Adequate Household Food Provisioning (MAHFP) District-wise Score

\begin{tabular}{|l|r|}
\hline \multicolumn{1}{|c|}{ Districts } & \multicolumn{2}{c|}{ MAHFP Score } \\
\hline Kohistan & 10.08 \\
\hline Shangla & 11.95 \\
\hline Swat & 12.00 \\
\hline Muzaffargarh & 10.03 \\
\hline
\end{tabular}

\section{Discussion}

According to Food Security Assessment Survey (FSA), 2016, 18\% of the population in Pakistan is undernourished which can be attributed to limited economic access of the poorest and most vulnerable to food.11 It's only normal that people don't always get what they want and desire and the choices are more constrained in adverse situations like poverty and disasters.

The five outputs clearly align with the overall purpose of the project, from production and access to nutrient rich diversified food to improving households' income and increasing their knowledge base regarding nutrition to easy access to markets and clean drinking water. Most effective activities were selected for the achievement of project outputs, that have contributed to the results. While all activities, carried out under each output have relevance to the respective output, the most outstanding was the diversified kitchen gardens and field days that have the most positive effect on the communities by increasing their access to nutritious vegetables, fruits and crops.

The projects (1086 and 1087) conducted in the provinces of Punjab and Khyber Pakhtunkhawa were successful in achieving their overall objectives to a great extent, evident from the HDD and IDD scores of the end line survey of the project. The average HDDS of Swat, Shangla and Kohistan increased from 3.5 (lower tercile) at baseline to 5.59 (medium tercile) at the end of the project, measured during the end line survey. IDDS increased for Pregnant and Lactating women from 2.6 (lower tercile) to 6.16 medium tercile) and 2.4 (lower tercile) to 5.4 (medium tercile) respectively while the IDDS for children under 2 years improved from 1.6 to 3.4. In Muzaffargarh the HDDS increased from 6 at baseline to 7.6 at the end of the project measured during the end line survey. The IDDS increased for Pregnant and Lactating women from 4.8 to 5.9 and 4.3 to 5.8 respectively while the IDDS for 
girls under 2 years improved from 3.2 to 4.6 and for boys under 2 years, from 3.5 to 4.3 .

Effectiveness of the projects was evident from the empowering target communities in improving their nutritional status with development of their capacities to plan and manage their access to and use of nutritious food during natural disasters. A combination of approaches grounded in the local realities and context has led to the successful achievement of results at the community level. Phase 2 of Food and Nutrition Security (FNS) project in both provinces was geared towards strengthening the best practices of Phase 1, strengthening and empowering community organizations and linking them with relevant duty bearers i.e. government departments at the local and district level. Both Lasoona and Doaba have harnessed the opportunity of increased nutrition focus in the government echelons with presence of approved multisectoral nutrition strategies at the provincial, district and union council levels. Mobilization of District Multisectoral Forums in KP and District Malnutrition Addressing Committees (DMACs) in Punjab have helped in making the project initiatives a part of government plans - diversified kitchen gardens have made quite an impact on the agriculture authorities. Nutrition training of Lady Health Workers, Extension Workers and school teachers have ensured sustained nutrition awareness among communities.

Behavior change communication (BCC) through social mobilization was the lynch pin of both the projects, none of the other activities could have gained traction and acceptance by the communities without BCC through social mobilization. Activities that raised the nutrition awareness of the target communities and convinced them to change their lifestyles were practicing dietary diversity in households, early initiation of breastfeeding and exclusive breastfeeding, diversified complimentary feeding of children, changing dietary patterns of pregnant and lactating women, diversifying, maintaining and expanding kitchen gardens, adopting and changing practices for food storage - which led to improvements of nutritional status of target communities are examples of efficient interventions.

Poverty and limited access to nutritious food are among the main drivers of malnutrition. Impact of both projects was depicted both economically and socio-culturally. They focused on increasing access, availability and utilization of nutritious food. The HDDS and IDDS improvement in the target areas, capacity building and implementation of kitchen gardens trainings on reducing pre and post-harvest losses, preservation of fruits and vegetables and development trainings are evidence of the success. An important change observed was in the improved status and participation of women in the family and social life. The projects have helped build the technical capacities regarding food and nutrition security in the implementing partners, while clarified the direction of FNS direction in Pakistan for WHH.

Sustainability was ensured in both projects by ensuring availability and accessibility of diversified nutrients within the target communities with economic and financial benefits in the form of Diversified Kitchen Gardens. Communities experienced the benefits of these kitchen gardens and expressed that kitchen gardens should be replicated and continued, after the end of the projects. In addition, awareness and capacity development regarding nutrition and food security of the target communities and the whole assistive network of trained LHWs, agriculture and livestock extension workers and peer educators linked with the communities for continued support and information and services, beyond project period was ensured.

Socio-cultural changes initiated by the projects' interventions were considered to make the projects self-sustainable but eighteen months was too short a period for bringing about any sustainable social change. Social norms addressed were women participation in decision making, care for pregnant and lactating mothers, colostrum feeding, exclusive breastfeeding women participation in community development, involvement of children in nutrition education.

Evaluation declared the projects to be successful with fulfillment of the objective with a considerable contribution the cause of Food Security in a country like Pakistan.

Conclusion

WHH and its partners have been successful in demonstrating an integrated development model for enhancing food and nutrition security. Project 1086 and 1087 were social change projects sowing the seeds of a major social paradigm shift - changing the status of women at household and community level.

Awareness regarding effects of malnutrition, value of balanced diet and nutritious foods through community volunteers, peer educators, social mobilizers and outreach workers played a pivotal role to bring about dietary behavior change at the household levels.

Communities were convinced to take up activities for increasing access and availability of diversified and nutritious food - planting diversified kitchen gardens, fruit trees plantation, use of organic fertilizers, sprays, trainings on reducing pre and post-harvest losses.

To safeguard, sustain and enhance this change, Lasoona and Doaba linked the community organizations with the local government departments. The efforts were met with a positive response by the government officials but continuous efforts are needed to institutionalize these initiatives.

WHH should focus its expertise and resources for bringing out a systemic change, enabling nutrition sensitive environment - policies and programs - a sustainable solution for reducing malnutrition in the country.

\section{Recommendations and Way forward}

1. Continue with the partnership approach in their future interventions as well.

2. Focus energies and resources at the policy and decision makers level, at national, provincial and local levels, to make the government system responsive to the needs of the communities.

3. We should harness this infrastructure by providing technical support and building the capacities for integrated multi-sectoral nutrition approach while strengthening nutrition interventions through government.

4. Making the collective voice of community, a vehicle for achieving a solution of their problems from relevant government departments, is the way of actual social empowerment. We should make it the core component replacing service delivery.

5. Undertake cost- benefit and or cost-effectiveness analysis of FNS projects, to understand its comparability with other community based developmental models of FNS, especially in South Asian context.

6. Focus on undertaking some robust intervention trial in the comparable communities, with 1st community - no intervention, 2nd community - complete intervention with community organizations and government mobilization, 3rd communityOnly intense government mobilization / engagement.

7. We should include food value chains and access to markets, through public private partnerships in future programs, as the role of private sector is critical for ensuring sustainable food and nutrition security.

\section{References}

1. https://www.welthungerhilfe.org/our-work/countries/ pakistan/ https://www.welthungerhilfe.org/

3. $\quad$ www.lasoona.org>projects

4. Swindale A, Bilinsky P. Household dietary diversity score (HDDS) for measurement of household food access: indicator guide. Washington, DC: Food and Nutrition Technical Assistance Project, Academy for Educational Development. 2006

5. Becquey E, Martin-Prevel Y, Traissac P, Dembélé B, Bambara A, Delpeuch F. The household food insecurity access scale and an index-member dietary diversity score contribute valid and complementary information on household food insecurity in an urban West-African setting. The Journal of nutrition. 2010;140(12):2233-40.

6. Chianca $\mathrm{T}$. The $\mathrm{OECD} / \mathrm{DAC}$ criteria for international development evaluations: An assessment and ideas for improvement. Journal of Multidisciplinary Evaluation. 2008;5(9):41-51.

$7 . \quad$ http://doabafoundation.com/

8. The LOT Quality Assurance Sampling (LQAS)Frequently Asked Questions https://coregroup.org/wp-content/ uploads/media-backup/documents/Workingpapers/ LQAS FAQ.pdf

9. Islam KF. SPATIAL DIMENSIONS OF FOOD INSECURITY IN. 2014

10. De Cock N, D'Haese M, Vink N, Van Rooyen CJ, Staelens L, Schönfeldt HC, D'Haese L. Food security in rural areas of Limpopo province, South Africa. Food Security. 2013 Apr 1;5(2):269-82. 
11. National Food Security Policy. June 2017. Ministry of National Food Security and Research Islamabad. Government of Pakistan

12. http://www.mnfsr.gov.pk/mnfsr/userfiles $1 /$ file/ $12 \% 20$ Revised $\% 20$ Food $\% 20$ Security $\% 20$ Policy $\% 2002 \%$ 20June\%202017.pdf

13. Global Nutrition Report 2018. Globalnutritionreport.org

14. The Lancet Series 2013

15. PDHS 2017

16. The economic consequences of undernutrition in Pakistan. 2017. SUN Secretariat, Ministry of Planning, Development and Reform. Islamabad.

17. Project End-line report

18. Development Statistics of Khyber Pakhtunkhwa 2017 Bureau of Statistics. P\&D Department, Government of Khyber Pakhtunkhwa. http://www.pndkp.gov.pk/wpcontent/uploads/2017/07/DEVELOPMENTSTATISTICS-OF-KHYBER-PAKHTUNKHWA2017.pdf

19. Project 1087 HDDS baseline report

20. Punjab Development Statistics 2016, Bureau of Statistics, P\&D Department, Government of Punjab. http://bos.gop.pk/system/files/Dev-2016.pdf

21. Food Insecurity in Pakistan. 2009. https://www.sdpi.org/ publications/files/food\%20insecurity $\% 20$ in $\% 20$ Pakistan $\% 202009 \% 20$.pdf
22. Integrated Context Analysis (ICA) On Vulnerability to Food Insecurity and Natural Hazards Pakistan, 2017. https://www.pdma.gov.pk/sites/default/files/Integrated\%2 0Context $\% 20$ Analysis $\% 20 \% 28 I C A \% 29 \% 200$ n $\% 20$ Vuln erability $\% 20$ to $\% 20$ Food $\% 20$ Insecurity $\% 20$ and $\% 20$ Natur al\%20Hazards\%20Pakistan\%2C\%202017.pdf

23. Kohistan is one of poorest districts in Pakistan. http://bisp.gov.pk/wp-content/uploads/2017/02/PovertyProfile-1.pdf

24. National Food Security Policy. June 2017. Ministry of National Food Security and Research Islamabad. Government of Pakistan. http://www.mnfsr.gov.pk/mnfsr/ userfiles $1 /$ file $/ 12 \% 20$ Revised $\% 20$ Food $\% 20$ Security $\% 20 \mathrm{P}$ olicy\%2002\%20June\%202017.pdf

25. Cost-benefit analysis versus cost-effectiveness analysis. https://www.undp.org/content/dam/rbas/doc/Energy\%20a nd\%20Environment/Arab Water Gov Report/Arab Wat er_Report_AWR_Annex\%20I.pdf

26. http://depts.washington.edu/gwach/wp-content/uploads/ 2014/04/11.-Cost-Cost-effectiveness_Levin.pdf

27. Planning and costing for the acceleration of actions for nutrition: experiences of countries in the Movement. 2014. https://scalingupnutrition.org/wp-content/uploads/2014/ 05/Final-Synthesis-Report.pdf 